\title{
ENTREVISTA COM DILENE RAIMUNDO DO NASCIMENTO
}

\section{Eliza Vianna* Gabriel Lopes**}

É muito comum que estudantes olhem para seus professores e não consigam imaginar que estes também foram estudantes. Estar diante de um profissional com a carreira consolidada muitas vezes não nos permite dimensionar a trajetória que nela resultou. A pesquisadora Dilene Raimundo do Nascimento, grande referência na área de História das Doenças, nos recebeu em sua residência e nos contou um pouco de sua história, que se confunde com a própria formação do campo de estudo. Assistente social, médica, sanitarista e historiadora, a pesquisadora narra o percurso dessa formação complexa e interessante.

Dilene Raimundo do Nascimento se graduou em Medicina pela Faculdade de Medicina da Escola Técnico Educacional Souza Marques em 1976 e em Serviço Social pela Universidade Federal Fluminense em 1970, mestrado em Saúde Coletiva pela Universidade do Estado do Rio de Janeiro em 1991 e doutorado em História pela Universidade Federal Fluminense 1999. Seu aperfeiçoamento como pesquisadora, bem como grande fomentadora da história das doenças no Brasil e contribuições para o campo, se deram de sobremaneira no período em que atuou como pesquisadora na Fiocruz de 1987 a 2019, onde também atuou como professora e orientou diversos trabalhos de mestrado e doutorado. Dilene permanece como docente colaboradora na Fiocruz, no programa de Pós-Graduação em História das Ciências e da Saúde, da Casa de Oswaldo Cruz.

Entre as principais doenças a cujo estudo histórico se dedicou, destacam-se a tuberculose, a Aids, a poliomielite, a hanseníase e a peste. Do ponto de vista teórico, são importantes suas reflexões sobre a representação social das doenças. Suas principais publicações são a coletânea, Uma história brasileira das doenças - que já está em seu 8o volume; Pestes do século XX: tuberculose e Aids no Brasil (2005), Hanseniase: a voz dos que sofreram isolamento compulsório (2011); e A bistória da poliomielite (2010).

Em entrevista exclusiva para o Dossiê História da Saúde e das Doenças: experiências e perspectivas, realizada no dia 11 de outubro de 2019 em sua residência por Gabriel Lopes e Eliza Vianna, Dilene Nascimento fez reflexões sobre a sua trajetória como pesquisadora e analisou a estruturação do campo de história das doenças no Brasil. Além de comentar sobre a importância dos processos de representação das doenças em diversos grupos e personagens históricos, Dilene reafirmou como esse empenho intelectual é fundamental para entender a complexidade das doenças enquanto fenômeno social.

O produto é este material enriquecedor que traz importantes reflexões não apenas sobre história das doenças, mas também sobre as agências que configuram a formação de um campo do saber, reflexão fundamental para os estudos da História das Ciências. Fazemos votos de que a leitura seja proveitosa, principalmente para estudantes de graduação e pós-graduação.

\footnotetext{
* Doutora em História das Ciências e da Saúde pelo Programa de Pós-Graduação em História das Ciências e da Saúde (PPGHCS/COC/FIOCRUZ - 2018). Professora de História no Instituto Federal de Alagoas (IFAL). E-mail: eliza.vianna@gmail.com

** Doutorado em História das Ciências e da Saúde pela Casa de Oswaldo Cruz - FIOCRUZ (2016) com período de doutorado sanduíche no Department of the History of Medicine na Johns Hopkins University (2014/2015). Vencedor do primeiro lugar do Prêmio Oswaldo Cruz de Teses (Ciências Humanas e Sociais) em 2017. E-mail: gabriel.lopes.mailbox@gmail.com
} 


\section{1 - Dilene, você é médica sanitarista, assistente social e doutora em História. Como você enxerga a relação dessa formação com a sua trajetória profissional?}

Dilene Raimundo do Nascimento - É... bom eu acho que tem a ver uma coisa com a outra. Primeiro... fiz o curso de Serviço Social e me formei assistente social, apesar de que o meu objetivo era mesmo estudar medicina. Mas o preparatório para medicina era muito caro e serviço social... como eu era boa aluna, eu não precisei me preparar muito, pelo menos não tem física, não tem química na prova, né? Aí passei. Fiz o curso de Serviço Social na UFF [Universidade Federal Fluminense], mas quando eu estava no segundo ano do Serviço Social, eu tentei um vestibular para medicina. Fiquei excedente e, de toda forma, foi até bom, porque comecei a estudar Medicina depois de terminar o Serviço Social. Toda a turma excedente daquele ano, cuja prova vestibular foi no final de 1968 para começar em 1969... E foi o último ano que teve excedente, porque o governo resolveu eliminar essa figura e, no vestibular seguinte, começou a considerar as provas classificatórias e não mais eliminatórias. Assim, você era classificada até o número das vagas, se não passasse dentro das vagas, você não era nada, você simplesmente não entrava. Bem... mas nós fomos excedentes e ficamos dois anos batalhando para sermos absorvidos no curso de Medicina, tanto que a gente acabou criando, ou contribuindo, para que, uma escola de medicina nova fosse criada, que foi a Souza Marques, ali na Rua do Catete n⿳0 6 . Então nós, excedentes da Medicina e Cirurgia, fomos a primeira turma da Escola de Medicina da Souza Marques, como bolsistas do MEC.

Desde antes da época que eu estudava Medicina, eu também participava de alguma forma do movimento político, do movimento estudantil, no período da ditadura. E, próximo a me formar, eu só poderia escolher a especialização em Saúde Pública, que é uma coisa mais coletiva, é pensar a questão da saúde como direito da população e de forma mais coletiva, não a medicina curativa, individual. Por isso eu me tornei médica sanitarista. Como não tinha emprego nessa época, não tinha concurso, não tinha nada - era Chagas Freitas o governador no Rio de Janeiro naquela época - eu fui fazer concurso em São Paulo, na Secretaria de Saúde do Estado de São Paulo. Fui aprovada e tomei posse em 1980; fiquei sete anos em São Paulo: um ano na cidade de Paraguaçu Paulista e seis anos em São José dos Campos, trabalhando como médica sanitarista na rede de saúde do estado de São Paulo. A essa altura, a ditadura estava nos seus estertores. A abertura política "lenta, gradual e segura" iniciada no Governo Geisel foi finalizada no Governo Figueiredo. Então em 1985, a ditadura chegou ao fim com a eleição indireta de Tancredo Neves, com o compromisso de remover as leis e regulamentos autoritários da ditadura militar e convocar uma Assembleia Nacional Constituinte. Foi o início do processo de redemocratização no país. Tancredo Neves veio a falecer antes mesmo de assumir a presidência e quem assumiu foi o seu vice José Sarney.

Nisso, os meus contemporâneos de quando a gente estava no Rio de Janeiro fazendo o curso de Saúde Pública na Fiocruz, participando de um grupo de estudos de epidemiologia no IMS/UERJ, e fazendo trabalho político nas favelas via ambulatório médico tinham assumido cargos nos órgãos de governo. Hésio Cordeiro foi para a presidência do INAMPS [Instituto Nacional de Assistência Médica da Previdência Social], Sérgio Arouca assumiu a presidência da Fiocruz, Paulo Gadelha foi para a direção da Casa de Oswaldo Cruz, que foi criada em 1986... em suma, as pessoas estavam em cargos nas instituições de saúde e aí eu voltei para o Rio de Janeiro. Assim, em 1987, vim cedida para a Presidência do INAMPS.

A recém-criada Casa de Oswaldo Cruz precisava de pesquisadores da área da saúde. Como eu tinha participado de um projeto de pesquisa no Centro de Memória Social, da Cândido Mendes, 
cujo título era A história da assistência médica da classe trabalhadora no Brasil de 1870 a 1945, com uma equipe formada por historiadores, sociólogos e eu como médica, quando eu fui para São Paulo, o Paulo Gadelha entrou nesse projeto no meu lugar. Então ele me conheceu aí, em função desse projeto, e acenou com a possibilidade de eu ir para Casa de Oswaldo Cruz. Então fui para lá em junho de 1987. Inicialmente, fiz parte da equipe que estudava a gestão Hésio Cordeiro no INAMPS. Ao finalizar esse trabalho, as pesquisas em história da saúde e história das ciências na Casa de Oswaldo Cruz, me levaram a pensar no estudo de história das doenças, no sentido de juntar os conhecimentos que eu tinha - eu não tinha conhecimento de história exatamente (risos) eu tinha conhecimento das doenças, né? A instituição, em determinado momento, estimulou que todos os seus pesquisadores se qualificassem, até para facilitar a busca de recursos - porque se você é qualificado, titulado, você tem mais chances de conseguir recursos externos. Então fiz o mestrado em Saúde Coletiva, no IMS (Instituto de Medicina Social), e a seguir o doutorado em História na UFF [Universidade Federal Fluminense] para juntar o conhecimento das áreas. No mestrado eu tinha estudado a história da tuberculose e a Liga Brasileira contra a Tuberculose, mais especificamente. Quando eu terminei a dissertação sobre a história da tuberculose, defendida em 1993, a AIDS era o que você tinha na imprensa... Em todos os cantos, o que se falava era de AIDS, e com uma história, que, na época, eu achei, de certa forma, semelhante à história da tuberculose, guardando os devidos tempos né? Por que eu estudei a história da tuberculose do início do século XX, e a AIDS apareceu no final do século XX, e com uma trajetória própria. Mas o medo que causava na população, era o mesmo medo que causava na população em relação à tuberculose lá no início do século XX. A sociedade civil se organizar para combater e cobrar do Estado uma posição em relação à doença e aos doentes etc aconteceu em uma e em outra ocasião e também a questão do medicamento, pois o tratamento que se tornou efetivo em relação a tuberculose é uma combinação de três medicamentos e em relação à AIDS surgiram os antirretrovirais em 96, que também é uma combinação de medicamentos... Então resolvi estudar no doutorado uma comparação entre a tuberculose e a AIDS que depois se tornou um livro [As pestes do século XX. Tuberculose e Aids no Brasil: uma história comparada] publicado pela Editora Fiocruz, em 2005. Então eu acho que tem total conexão, digamos assim [Gabriel: “sua vocação social, saúde, doenças?”]. É exatamente, entendeu? Como assistente social, a gente ia para as comunidades para trabalhar com a população, e o trabalho técnico ajudava as comunidades a se organizarem para reivindicar melhorias para o coletivo. Então é uma coisa mais coletiva também. Saúde pública é coletivo... E a história, quando você pensa em história das doenças, na representação social da doença, e isso inclusive... provoca mudanças na trajetória das doenças e, na hora que você estuda a representação social das doenças, você compreende melhor qual o significado daquela doença, o que aquela doença representa para aquela comunidade, qual é o conhecimento mais efetivo em relação à doença. Por que, a partir da representação que se tem... até mesmo o tratamento vai ter mais ou menos adesão, então vai ser mais ou menos eficaz. [Gabriel] "isso já leva para a segunda pergunta" (risos).

2 - No âmbito da historiografia das doenças, discute-se a formação do campo decorrente de uma disputa com o saber médico, que durante muito tempo produziu narrativas sobre as doenças. Como historiadora e médica, como você enxerga a relação entre os dois campos do saber e como se deu sua aproximação com a História?

Dilene Raimundo do Nascimento - Que é a questão do campo de história das doenças (risos). 
Durante muito tempo as narrativas sobre doença e mesmo sobre saúde eram produzidas por médicos que as construíam do ponto de vista médico, isto é, sem problematizar a questão. Era um trabalho descritivo e com apologia dos feitos médicos. Quando você introduz a análise histórica para estudar a doença, por exemplo, você deixa de simplesmente descrevê-la do ponto de vista de sua história natural, biologizante, e passa a entendê-la como um fato social, o qual depende tanto do espaço e do tempo, como das características dos indivíduos e dos grupos atingidos. Portanto, você estabelece nexos entre as condições biológicas e a ordem social e, necessariamente, relaciona com processos sociais, culturais, econômicos e políticos mais amplos.

[Gabriel: “então só fazendo um desvio no nosso roteiro bem rápido baseado no que você acabou de falar é interessante porque, você participou de um período, de uma certa virada. Hoje em dia na produção de história das ciências no Brasil, a história das ciências biomédicas é a produção mais prevalente em termos de volume de produção, isso é muito por conta na Casa de Oswaldo Cruz né? $\mathrm{E}$ do programa de pós-graduação... Você teve que lidar muito com literatura médica nesse início? Quer dizer, com a história que os médicos já tinham escrito para fazer sua própria história? Como é que foi isso?’]

Dilene Raimundo do Nascimento - Eu li Lourival Ribeiro para os estudos da tuberculose, por exemplo. Lourival Ribeiro foi um tisiologista, de grande importância, tem vários livros publicados, inclusive sobre a Fundação Ataulfo de Paiva, mas a narrativa dele é aquela que acompanha a doença do ponto de vista médico, mas para ele fazer isso ele reúne uma imensidão de fontes, e até eu disse isso em algum momento na tese - que apesar da narrativa partir do ponto de vista médico, a contribuição de fontes é da maior importância. Todos eles... Bem depois veio a aproximação com História e foi isso... Eu estava na Casa de Oswaldo Cruz que trabalha com história. A finalidade da Casa era a História das Ciências Biomédicas, que tinha isso descrito literalmente, e tinha também outro propósito, que seria estudar a história da Fiocruz. É história... É uma unidade que trabalha com a história. Então precisava esse conhecimento de história que eu não tinha, então por isso eu fui fazer o doutorado, por isso a minha aproximação com a história, porque eu fui trabalhar numa instituição que trabalha com a história.

Eu me lembro de uma questão interessante posta pela banca: como a proposta da tese era comparar a tuberculose no início do século XX e a Aids no final do século XX, alguém da banca não me lembro exatamente quem, [perguntou] Mas como você pensa em comparar tempos tão distantes? Eu falei, olha, eu sei que tem elementos comparáveis em relação a uma e a outra doença, agora essa questão específica que você está colocando eu vou aprender no doutorado (risos). Porque eu não era historiadora, né? Como resolver isso? O doutorado ia me ensinar né? Assim as pesquisas e as aulas... tanto que eu fiz sete disciplinas, por não ser da área de história eu estudei todas as disciplinas que tinha no doutorado, mas foi ótimo, porque aprendi muito. Inclusive fiz um grupo bom também, de colegas do doutorado que também ajudaram muito. Eram todos historiadores, em suma, eu só ganhei... com esse tempo no doutorado. Fiz no tempo, mas fiz muitas disciplinas.

3 - Entre as principais doenças que você estudou, estão tuberculose, aids, poliomielite, hanseníase, dengue, peste. Como você descreveria a importância de cada uma dessas doenças para a historiografia das doenças? Nos últimos anos, você vem trabalhando com o conceito de representação social das doenças. Como você definiria esse conceito? 
Dilene Raimundo do Nascimento - Eu começaria dizendo o seguinte: a saúde e a doença tratadas como objetos da História têm sido tema de vários trabalhos publicados. Com diferentes abordagens e um amplo leque de tipos de fonte, a saúde e a doença são problematizadas por meio de análises históricas que contribuem para revelar as relações sociais e políticas engendradas por determinada sociedade, pela forma como reage e interage com determinadas condições de saúde e com as doenças existentes. Ao problematizar a história de uma doença, como eu disse anteriormente, você estabelece nexos entre as condições biológicas e a ordem social e, necessariamente, relaciona com processos sociais, culturais, econômicos e políticos mais amplos.

Passando para o conceito de representação social das doenças, eu repetiria o que já disse em um pequeno artigo que publiquei no Boletim Eletrônico da Sociedade Brasileira de História da Ciência ( $\mathrm{n}^{\circ} 2$, março de 2014): Entendemos por forma de representação um conjunto de imagens, sentimentos, configurações plásticas ou literárias, bem como valorações, pelo qual, apesar de seus diferentes modos de manifestação, doenças específicas vêm sendo ao longo do tempo representadas nas mentalidades coletivas. E, citando Claudine Herzlich (1991, p.23), "é englobada na imagem de uma sociedade que a doença adquire uma significação". De toda forma, o estudo da representação social das doenças deve articular a patologia de uma época, o contexto histórico e ideológico onde ela ocorre e o estágio de desenvolvimento da medicina, por entender que existe uma mão dupla entre a realidade social e histórica e a doença.

Então pensar a importância da historiografia dessas doenças que eu estudei, pelo que foi dito até agora, espera-se que elas revelem de certa forma, a realidade social onde elas ocorrem. Assim, por exemplo, a tuberculose, que transitou da concepção de mal romântico a flagelo social, mostra como sua representação está intrinsicamente vinculada à realidade social. No final do século XVIII e meados do XIX, a concepção que se tinha da tuberculose era de mal romântico, vista como a doença da paixão, a paixão que diferenciava o artista, que sonhava ter a tuberculose, porque aquela facies pálida emprestava uma aura romântica e ele achava que produziria mais. Mas esse sentimento logo era questionado, porque a tuberculose à medida que avança, ela debilita e o artista ficava sem forças para produzir. Essa concepção perdurou até se verificar as consequências da Revolução Industrial: as condições de trabalho e de vida daqueles trabalhadores fabris, com uma jornada de trabalho extremamente aumentada, num local de trabalho altamente insalubre, debilitava aqueles trabalhadores. Dessa forma, a tuberculose começou a ser vista como flagelo social, reforçado pelas estatísticas da época, por sua altíssima incidência entre os trabalhadores.

A poliomielite, quando começou a se manifestar de forma epidêmica no início do século $\mathrm{XX}$, veio questionar paradigmas: doença infecciosa, transmissível era associada a sujeira e sujeira é coisa de pobre (Ver o livro de Mary Douglas, intitulado Pureza e Perigo). Mas sua forma paralítica incidiu inicialmente entre crianças ricas e os cientistas procuraram várias explicações para esse fenômeno, atribuindo à mosca o papel de vetor, que transitava nas casas pobres e carreavam o germe para as casas ricas, infectando as crianças das classes abastadas. O paradigma existente até então contribuiu para o atraso do conhecimento sobre a doença. Somente na segunda metade do século XX se descobriu a vacina antipoliomielite, primeiro a vacina Salk e depois a Sabin. A partir daí foi possível estabelecer políticas relacionadas ao controle da doença, mas foi necessário uma forte decisão política para implementar campanhas de vacinação que levou à certificação de erradicação do poliovírus selvagem nas Américas, incluído aí o Brasil, em 1994. Logo começaram a surgir os casos de Síndrome Pós Pólio, que é um outro capítulo da poliomielite.

No final do século XX, a re-emergência e emergência de epidemias colocaram em xeque, por 
um lado a precariedade das estruturas de saúde pública, no caso da dengue, e por outro a biomedicina, no caso da AIDS.

A alternância de erradicação e reinfestação do vetor da dengue, o Aedes aegypti, caracteriza a história da doença no Brasil. Os primeiros casos foram registrados na cidade de Boa Vista, Roraima, no início da década de 1980. Nas décadas seguintes o país deparou-se com ondas epidêmicas que causaram grande aumento da ocorrência de casos que gradualmente passaram a atingir todas as unidades da federação. Houve um grande crescimento da doença, principalmente na década de 1990 e 2000, porquanto em 1980, apenas 12 municípios estavam infestados pelo Aedes aegypti mas, ao fim de 1998, esse número já havia aumentado para aproximadamente 2.910. Em 2001, 3.587 municípios das 27 unidades federadas encontravam-se infestados e a transmissão da infecção já ocorria em 2.262 municípios de 24 Estados. E a prevenção das epidemias não ocorria, porque havia uma discussão política sobre quem era o responsável por eliminar os mosquitos, isto é, quem era o 'pai do mosquito'. E a cada epidemia, que as autoridades da saúde negavam no seu início, aumentava o número de acometidos pela doença.

A Aids é considerada o grande mal do fim do século XX. Nesse momento, acreditava-se que, no tocante às doenças infecciosas, tudo estava revelado e, portanto, a luta contra esses males estaria praticamente ganha, uma vez que haveria meios de controlá-los sem maiores dificuldades. A AIDS veio contradizer essa crença. E trouxe uma carga muito dramática na sua representação ao surgir no cenário público como sinônimo de morte. Não só isso, mas, como diz Susan Sontag, reveladora da sexualidade daqueles por ela acometidos, porque a doença foi representada como doença gay.

\section{4 - Recentemente você escreveu um texto sobre temas sensíveis e História Oral sob a pers- pectiva das doenças. Gostaríamos que você falasse um pouco mais sobre a relação entre a sensibilidade do(a) pesquisador(a) no processo da pesquisa.}

Dilene Raimundo do Nascimento - Eu e Eliza escrevemos um artigo sobre temas sensíveis e história oral, sob a perspectiva da experiência das doenças, intitulado "História Oral, sensibilidades e história das doenças", atendendo à professora Ângela de Castro Gomes que nos convidou para fazer um capítulo para o livro História Oral e historiografia: temas sensiveis, que ela vai publicar em conjunto com outra colega. A gente trabalhou com a questão da Aids e selecionou duas das entrevistas constantes do Acervo de depoimentos orais A Fala dos Comprometidos, que está guardado pelo Departamento de Arquivo e Documentação da Casa de Oswaldo Cruz. Esse Acervo foi constituído pelas entrevistas realizadas para a minha tese. Ele está acessível a outros pesquisadores interessados no tema.

Relembrando as entrevistas, eu diria que é uma questão muito sensível lidar com a emoção do entrevistado. Então, eu diria sim, que foram as entrevistas de história oral para o projeto da Aids que mais emoção me passaram, todas sem exceção, sem exceção A gente entrevistou duas mães, uma que o filho havia falecido em 1986, e uma outra mãe, que o filho estava vivo e foi beneficiado com os antiretrovirais. A gente entrevistou um rapaz soropositivo, que já tinha desenvolvido a Aids mas, a doença nele ainda era bastante incipiente, ele não desenvolveu a AIDS do jeito que a gente conheceu na década de 80. Quatro mulheres soropositivas, de diferentes faixas etárias e ocupação. Entrevistamos gestores do Programa Nacional de AIDS, jornalistas que escreviam sobre Aids em revistas e jornais, gestores do Grupo pela Vidda, que foi uma das ONGs do começo da questão da Aids... e todas muito, muito... o processo é doído, alguns é... atingiram mais fortemente a gente, e 
outros menos. É o que eu digo para os meus alunos e para quem trabalha comigo: até hoje eu me emociono muito com uma das entrevistas da Aids... porque essas entrevistas foram realizadas um momento que a carga dramática da Aids ainda estava muito presente para todos, entendeu?

Um dos rapazes que a gente entrevistou, era da Marinha, ele trabalhava na praça Mauá e morava na Baixada, eu não me lembro exatamente onde, então todo dia ele pegava o ônibus, lá na casa dele, para ir para o trabalho. E aí ele se viu soropositivo e naquela época as Forças Armadas demitia, exonerava. Mas depois, com o trabalho das ONGs e do próprio Programa Nacional de Controle da Aids, que foi exemplar né? Conseguiu-se criar leis que tornou essa medida proibida, por exemplo. Na entrevista ele disse o seguinte: ele não queria dizer para os pais que ele era soropositivo, então diariamente ele saia de casa, normalmente, para o trabalho. Pegava o ônibus dele e ficava rezando para que o congestionamento da Avenida Brasil fosse muito intenso Por que o trânsito, em direção ao centro fica parado na Avenida Brasil e ele todo dia saia de casa rezando para que ficasse parado mais tempo ainda, para ele precisar de menor tempo para ficar andando na cidade à toa para voltar para casa, entendeu? Até que, algum amigo da onça dele mandou uma carta anônima para mãe dele dizendo que ele era soropositivo. Ela o apoiou e ele não precisou mais dessa farsa. Você pensar uma coisa dessa, rezar para o congestionamento (risos). [Gabriel: é impensável, ninguém quer isso para sua vida né ?]

É impensável! É um significado muito diferente para ele, o congestionamento da Avenida Brasil para ele era um benefício, digamos assim entendeu? E assim, a gente, ao mesmo tempo que está ali como pesquisador... a gente tem que ter uma empatia muito grande por aquela pessoa que a gente está entrevistando. Isso em qualquer situação.

5 - Você recentemente se aposentou como pesquisadora na Casa de Oswaldo Cruz, instituição de referência na área de História das Ciências e da Saúde cuja criação esteve ligada ao processo de redemocratização brasileiro, defesa da saúde como direito universal e criação do Sistema Único de Saúde. Como você enxerga a relação entre a História das Doenças e a Saúde Pública hoje? Em outras palavras, por que é importante estudar História das Doenças?

Dilene Raimundo do Nascimento - Então... aí sobre aposentadoria, né... eu me aposentei agora dia 31 de Maio, por isso inclusive a entrevista, se não estaria fazendo um artigo para publicar na revista (risos), entendeu? Aí eu pude me furtar do artigo porque já estou aposentada, é... Mas eu inclusive continuo orientando no programa. Tenho duas orientandas, uma de doutorado e uma de mestrado, que vou até o final com elas. E estou fazendo uma pesquisa para outra unidade da Fiocruz, que deve ir até dezembro. Então ainda tem esse trabalho de pesquisa. Estou escrevendo um livro sobre a história da peste, sem prazo para terminar. Também estou escrevendo um livro sobre a história da criação da Escola de Medicina Souza Marques, sobre a primeira turma que ajudou a criar essa escola de Medicina, que deve ser editado em janeiro de 2020.

Como eu enxergo a relação entre a história das doenças e a saúde pública hoje é... Eu acho assim essa, essa análise da história das doenças, essa análise da representação social das doenças para os grupos específicos, pode contribuir com a Saúde Pública, no sentido de estudar a percepção que a população tem de determinadas doenças que são objeto de políticas da Saúde Pública.

Eu acho que vale a pena colocar também nessa entrevista a referência do artigo que a gente publicou na revista de São Paulo. Nós temos um grupo de estudos sobre a história das doenças, que já tem uns 10 anos, e foi no grupo que escrevemos esse artigo. Passamos quase dois anos 
escrevendo (risos), porque a escrevemos, literalmente a 4,6...(contanto) 8 mãos: Eliza Vianna, Mônica Moraes, a Danielle Fialho e eu. [Gabriel: Qual foi o assunto?] É uma discussão teórica sobre representação social das doenças.

A referência do artigo é: Nascimento, D. R.; Vianna, E. S.; Moraes, M. C.; Silva, D. S. F. "O indivíduo, a sociedade e a doença: contexto, representação social e alguns debates na história das doenças". Khronos, Revista de História da Ciência, no 6, pp. 31 - 47. 2018. Disponível em $<$ http://revistas.usp.br/khronos $>$.

6 - Nos últimos anos tem-se falado muito de saúde mental na pós-graduação e debatido sobre a pressão no ambiente acadêmico. Além de excelente pesquisadora, você é conhecida por ser uma ótima orientadora. Em sua opinião, o que é preciso para orientar bem um(a) estudante?

Dilene Raimundo do Nascimento - Primeiro ouvir, depois falar (risos), falar também, bastante (risos). Então, eu acho assim que orientador tem obrigação, é papel do orientador acompanhar o aluno, entendeu? Tem que acompanhar, tem que perceber onde que o aluno está com mais dificuldade. Orientar no caminho que deve tomar em relação às fontes, que procure relacionar as fontes com seu objeto, discutir referencial teórico para a sua pesquisa, também até onde eu posso, porque eu também não sei tudo, porque quem sabe o assunto da tese ou da dissertação é o próprio aluno. Ele que sabe mais, sabe mais do que eu, entendeu? Eu acho que o que é preciso é não deixar o aluno largado em hora nenhuma! E ver o aluno como pessoa, para além de ser aluno, ele é uma pessoa. Claro que não dá para você ficar... Não é botar no colo entendeu? Mas é estar preocupado com ele como pessoa também, entendeu? Então eu acho que é isso. E dizer, também, ser claro, assim: "isso eu não sei”, você que vai estudar. Ou, isso eu sei eu acho que você deve ir por aqui por ali e tal...

7 - Como você avalia a sua trajetória até aqui como pesquisadora e educadora que estimulou a pesquisa de história da saúde e das doenças em diversas gerações e instituições (comentaríamos sobre a importância de falar sobre o Amapá). O que você acha?

Dilene Raimundo do Nascimento - Como avalio, eu diria positivo, né, é claro (risos). Mas eu diria o seguinte, foi uma luta. Foi uma luta. Você adentrar uma nova área, no meu caso, ter formação em Medicina e entrar na área de História. Você passa um tempo se perguntando: o que eu estou fazendo aqui? Eu quero os meus pacientes... Mas, se você persiste, uma hora você se converte em definitivo e abraça uma nova carreira. No meu caso, deixei de ser médica e me tornei historiadora, quer dizer, pesquisadora em história das doenças.

Por acaso, no momento da minha conversão, uma colega, a quem eu respeito muito também, me disse o seguinte: - Olha você pode dizer o que você quiser, você pode achar que você está pesquisando história das doenças, enquanto você não publicar, não vai adiantar nada. Aí eu falei: ah é? Ela falou: é, você tem que publicar, porque só você publicando que o outro vai ler e aí você pode criar um campo, uma área de estudo... Se os seus pares não lerem, se seus pares não fizerem as críticas positivas ou negativas, não vai adiantar. Aí comecei a trabalhar no sentido de publicar tudo, porque até então ficava só no âmbito da COC.

Um caminho bastante importante para a difusão do campo foi a ANPUH. No Encontro Regional-Núcleo RJ, realizado em 2000, em Niterói, inscrevemos o GT História das Doenças, onde 
se discutiu o tema geral de "A multiplicidade de perspectivas na História das Doenças", sendo apresentado um painel da produção até então no campo de estudo. Nesse evento, eu conheci a Anny Jackeline Silveira e a Rita de Cássia Marques, que são da UFMG. Conversamos durante o congresso e elas se animaram com a ideia de criar um grupo de trabalho da ANPUH em Minas Gerais. Então esse foi o primeiro GT criado em História das Doenças, na verdade é GT de História da Saúde e das Doenças, por entendermos que seria mais amplo. Na ocasião, eu preferia que fosse somente de História das Doenças, porque eu ainda estava no processo de construir e consolidar o campo da história das doenças, mas entendi que restringiria, em se tratando de um GT da ANPUH. Hoje nós temos GT de História da Saúde e das Doenças, além de Rio de Janeiro e Minas Gerais, também em Goiás, Ceará e no Paraná.

Outro caminho que busquei foi organizar seminários de História das Doenças e a publicação de uma coletânea que ficou intitulada Uma história brasileira das doenças. Nessa empreitada, a parceria com a professora Diana Maul, da UFRJ, foi preciosa. Em 2004, realizamos o $1^{\circ}$ Seminário de História das Doenças, no Rio de Janeiro, e lançamos o primeiro volume da coletânea. A cada 2 anos, organizamos um seminário e lançamos os 3 primeiros volumes da coletânea, como resultado dessa parceria.

Você me perguntaria: como fizemos para reunir pesquisadores de história das doenças para escreverem no livro se era uma área que ainda estava se formando e nem tinha ainda uma rede de pesquisadores? - Pesquisamos as teses e dissertações no site da Capes e do CNPq, publicações no site da ANPUH e em revistas que sabíamos a priori que publicavam artigos correlatos. Enviamos convites e vários nos responderam e enviaram artigos.

Com os congressos nacionais da ANPUH, onde inscrevíamos Simpósios Temáticos de História da Saúde e das Doenças, e com a realização dos seminários de História das Doenças, no Rio de Janeiro, fomos ampliando os contatos com pesquisadores que tematizavam a doença. Assim, em 2013, inauguramos uma nova parceria institucional, desta feita com o professor Sebastião Pimentel Franco, da UFES. Ele me convidou para organizarmos o $1^{\circ}$ Colóquio de História das Doenças, na UFES, e, a partir daí, temos organizado anualmente esse colóquio. Demos continuidade à publicação da coletânea, agora junto com a UFES, e, neste ano de 2019, tivemos o VII Colóquio e publicamos o $9^{\circ}$ volume da coletânea Uma bistória brasileira das doenças.

Tivemos, mais recentemente, uma parceria pontual, mas bastante profícua, com o professor André Mota, diretor do Museu de História da Medicina da Faculdade de Medicina da USP. Realizamos o $1^{\circ}$ Simpósio Nacional de História das Doenças e das Artes de Curar, na Faculdade de Medicina da USP, para o qual convidamos alguns pesquisadores que trabalham com o tema e tivemos muitos trabalhos inscritos. Como um dos resultados, o professor André Mota conseguiu a publicação do dossiê História das Doenças e das Artes de Curar na Khronos - Revista de História da Ciência.

Outro caminho que faz circular conhecimento é a participação em bancas seja de mestrado seja de doutorado.

Assim, acho que hoje podemos dizer que nacionalizamos o estudo de História das Doenças e o campo se consolidou.

Finalizando, espero que esse dossiê seja mais um caminho para a difusão dos estudos em História das Doenças, em especial dentre os pesquisadores e alunos do Amapá. 